Contents List available at Volkson Press

Water Conservation and Management (WCM)

Journal Homepage: https://www.waterconservationefficiency.cor

ZIBELINE INTERNATIONAL

\title{
To Assess the Trends of Living and Poverty in a Desert Climate
}

\author{
Muhammad Afzal', Muhammad Asim Rizwan ${ }^{2}$ \\ ${ }^{1}$ Centre of Excellence in Water Resources Engineering, University of Engineering and Technology Lahore, Pakistan. \\ 2Institute of Geology, University of the Punjab. Corresponding author's email:afzelbutt@gmail.com
}

This is an open access article distributed under the Creative Commons Attribution License, which permits unrestricted use, distribution, and reproduction in any medium, provided the original work is properly cited

\section{ARTICLE DETAILS}

Article history:

Received 12 August 2016

Accepted 12 December 2016

Available online 20 January 2017

Keywords:

Desert; Low rainfall; Water scarcity; poverty line; livestock; Toba; Kund

\section{ABSTRACT}

Pakistan is a developing country having about $17.2 \%$ of the population below poverty line and its economy mainly depends on agriculture. Cholistan desert is one of the areas with extreme dry weather conditions in the country, well known for wide spread geographical area with large not in use lands. The population belongs to the poorest areas of the province with projected population of 0.185 million up to 2015. In this study a survey of 17 villages was conducted to gather information regarding population and their economic condition. Poverty status in the area with reference to the International Monetary Fund and Bureau of Statistics of Pakistan has been assessed with inflation rate up to year 2014. The average family size of the area is 6.6 and per capita income per month was PKRs.2309, so the Official Poverty Line came out as PKRs. 15,124 per household per month. During the field survey of the targeted 17 villages, it was observed that $95 \%$ of targeted population was below the poverty. On the other hand, the rest of only $5 \%$ fall above the poverty line as their earning was above PKRs. 15,124 per month. Income of 100 percent population was below US\$1.00 per day. Livestock is the main source of income of the targeted community, but they were unable to use it in full potential because of unavailability of water. On the other hand, the off farm income was very low due to scarcity of resources \& employment opportunities. People neither able to get a proper livelihood in their settlements nor ready to leave desert area because livestock rearing is their major occupation which is depending on "Tobas" and grazing land.

\section{INTRODUCTION}

Pakistan is an arid country and agriculture is the backbone of its economy. In rainfed areas like Cholistan, the life is dependent on the rainfall amount collected in small ponds locally called as Tobas Due to low income and low living standards, poverty is the main issue of Cholistan. According to FAO 2009, the hungry people on the globe are roughly 15 percent of the estimated world population. Poverty is defined as "a state or condition in which a person or community lacks the financial resources and essentials to enjoy a minimum standard of life and well-being that's considered acceptable in society" (www.studymode.com). The incidence of food poverty is higher in rural areas (35\%), than in urban areas (26\%), both in terms of per capita incomes and consumption expenditures (IFAD, 2010). The main reason of higher poverty in rural population is the unequal distribution of land and water availability. Pakistan's country partnership strategy (2009-2013) indicated that the proportion of the population living below the poverty line fell sharply from $34.5 \%$ in FY 2001 to $22.3 \%$ in FY 2006. Two poverty lines are used mostly, relative and absolute poverty line. Out of these poverty lines, the absolute poverty line is more relevant to under developed countries like Pakistan (www.thejaps.org.pk).

The Head Count Ratio (HCR) is a crude measure of poverty because it completely ignores the gap in incomes from the poverty line and the distribution of income among the poor (Khalid Zaman \& Bashir Ahmad Khilji, 2014). In Pakistan the official poverty is estimated by using consumption based methodology, and the report shows that the poverty has declined from $22.3 \%$ in $2005-06$ to $12.4 \%$ in 2010 11. The Government has formulated short and medium term plans of economic growth. The Vision 2025 is formulated to increase the per capita income from $\$ 1,299$ to $\$ 4,200$ and bring down poverty from $49 \%$ to $20 \%$. In Pakistan official poverty line is calorie based, and consumption based absolute poverty is estimated after converting the household consumption level to adult equivalent based on recommended nutritional requirements of 2350 calories per person per day and providing almost equivalent amount for other basic needs (www.studymode.com).

South Punjab is relatively under developed and poor part of the Punjab province. It has lower population density as compared to the rest of the Punjab. As per available statistics on poverty, $43.1 \%$ of the population is below poverty line compared to $27.7 \%$ of Punjab. Cholistan falls in southern part of Bahawalpur Division with majority of household extreme poor depending exclusively upon livestock for their livelihood. The two most serious constraints faced by Cholistan communities and their herds are the lack of water and shortage of fodder which cause their poverty. Cholistan, in general, is a sandy desert with erratic rainfall, high temperature, high evaporation rate etc. There are patches of arable lands, but agricultural activities are very rare due to not availability of any permanent or dependable sources of water supply and livestock is the main source of income. Groundwater is brackish and cannot be used even for animal drinking. However, along the periphery of Cholistan, where surface water sources are available, agriculture is the major occupation. The location map is shown in Figure 1.

\section{Figure 1. Cholistan location map.}

According to Agricultural Census Report (2006), the population of Cholistan was 0.155 million, and further projection up to 2015 at a growth rate of $2.0 \%$ per annum, the total population of Cholistan was estimated to be 0.185 million. Cholistan has a peculiar nomadic and transhumant culture. The nomadic people stay in the desert till the depletion of water collected in Tobas during the monsoon. The Tobas (shallow excavated water ponds) provide an important focus for temporary settlements, where people along with their animals congregate for a period of 3 to 4 months. Tobas are located 
throughout the area and consequently, there is a wide dispersion of both people and animals. Traditional housing of the population is the "Gopas" which are made of leaves and branches, trees etc. Sanitation and drinking water supply are rudimentary in nature or non-existent at the Toba settlement as shown in Figure 2. The population in the area belongs to the poorest areas of the province. Irrigated agriculture development in the area shall bring prosperity to this downtrodden population.

\section{Figure 2. Features of Cholistan.}

Many scientists have worked to calculate poverty lines in Pakistan in rural and urban areas (Jafri and Khattak (1995), Malik (1988), Shirazi (1993), Anwar and Qureshi (2002), Chaudhry (2003), Sabir et al, (2006)). Akhtar et al., (2015) determined the incidence, depth and severity of rural poverty in Punjab. Ali et al. (2015) used Poverty Equivalent Growth Index (PEGR) to study poverty levels among non-farming and farming rural households. The main objective of this study was to assess the initial poverty status and the major constraints in improving the socio-economic status of the inhabitants of Cholistan.

\section{MATERIALS AND METHODS} used.

To assess poverty status both primary \& secondary data was

\subsection{Collection of primary data}

To assess the socio-economic condition of the people living on the periphery and the interior of Cholistan desert, a field survey was carried out in the year 2015. Group discussions with nomads, local representatives and farmers were held to capture the social and economic standards. Moreover, to record the information a structured questionnaire was developed and pretested in the field.

\subsection{Collection \& review of secondary data}

Secondary data was collected from Punjab Irrigated Agriculture Investment Program (PIAIP). Literature and publications available on the socio-economic status of the people and information related to the study area were reviewed.

\subsection{Sampling procedure}

Permanent settlements in the desert area of Cholistan are limited. Most of the population is settled around the periphery and interior desert is only used for nomadic lifestyle. Keeping in view of the objectives of the study and to get the representative sample, 20 settlements were selected by the simple random sampling method. Out of total $3(30 \%)$ villages selected from the interior desert, $11(55 \%)$ from periphery while $3(15 \%)$ villages from the irrigated area of Cholistan. The purpose of selecting 3 villages from the irrigated area was to compare the circumstances with the desert area. The detail of villages selected for the study is shown in the Table 1.

\section{Table 1. Sampled villages of the study area.}

\section{RESULTS AND DISCUSSION}

\subsection{Poverty situation in South Punjab}

There are three divisions named as Bahawalpur Division, Dera Ghazi Khan Division and Multan Division in southern Punjab. Southern Punjab is relatively underdeveloped and poor part of the Punjab province with lower population density as compared to the rest of the Punjab. As per the available statistics on poverty, $43.1 \%$ of the population of South Punjab is living below the poverty line compared to $27.7 \%$ of Punjab which is below the poverty line.

\subsection{District indicates multiple deprivations}

A measure of deprivation is related to how the people live. The relative deprivation approach to poverty examines the indicators of deprivation, which are then related back to income levels and resources. According to the Districts Indices of Multiple Deprivations report for Pakistan 2011, Bahawalpur, Bahawalnagar and Rahim Yar Khan Districts are classified in the high deprived against the selected indicators. The report considers 17 indicators into five groups of composite indicators reflecting deprivation in education, health, housing quality, housing services and economic.

3.3 Population and demographic characteristics According to the results of the survey, total households of the sample villages and its surroundings were 2355 with total population of 16345 persons. The average family size was founded as 6.9. The key informants mostly were the Lambardars and the detail of the selected villages is provided in the Table 2 .

Table 2. Overall population and average family size of the selected villages.

\subsection{Poverty situation in Cholistan}

The economy of Cholistan depends on non-sustainable and nondependable source of rainwater. Economically, people are not well off. For about six months, when their "Tobas" come dried up they have to move to periphery of the desert or irrigated area. Animals have to be sold in nearby towns as cattle markets are not available nearby and therefore they could not get the right price of their cattle and milk. Furthermore, drought and long summer add misery to their lives. During this period, some of the family members look for some additional jobs to supplement income of their family. Daily paid labour is the best choice for them. For additional income to, animals are sold, and at the end of the day they are left with next to nothing. The survey indicates that there has been a change in the attitudes towards earning. Some adult family members, visit cities and town regularly for daily labour and some do farming.

Poverty Status in the study area with reference to the international Monetary Fund (IMF) and Bureau of Statistics of Pakistan, inflation rate up to year 2014 has been assessed. The average family size of the project area was 6.6 and per capita income per month was PKRs.2309, the Official Poverty Line (OPL) came out as PKRs. 15,124 per household per month. During the field survey of the targeted 17 villages, it was observed that $95 \%$ of the population was below the poverty line (PKRs.15124). On the other hand, the rest of only $5 \%$ fall above the poverty line as their earning was above PKRs. 15,124 per month. Income of 100 percent population is below US $\$ 1.00$ per day. The detail of income level of people living in different parts of Cholistan is shown in Table 3. Livestock was the major source of the income of the targeted community, but they were unable to bring it in use is full in a potential way because of unavailability of water. On the other hand, the off farm income was very low due to scarcity of resources \& employment opportunities. People neither able to get a proper livelihood in their settlements nor ready to leave desert area because livestock rearing is their major occupation which is depending on "Tobas" and grazing land of Cholistan. While, the situation in the irrigated is Cholistan is better where $89 \%$ people are below poverty line.

Table 3. Income level of the villages selected for survey.

\section{REFERENCES}

[1] Ali, I., A. Barrientos and A. Saboor. (2015). Pro-poor growth across different agro-climatic zones of rural Pakistan. Pak. J. Agri. Sci., Vol. 52(2), 495-501. Available at http://www.pakjas.com.pk/papers\%5C2445.pdf

[2] Anwar, T. S. and K. Qureshi (2002). Trends in absolute poverty in Pakistan: 1990-91 and 2001.The Pakistan Dev. Rev., 41 (4): 859-878. Available at http://www.thejaps.org.pk/docs/v-2502/34.pdf

[3] Chaudhry, Imran S. (2003). 'An Empirical Analysis of the Determinants of Rural Poverty in Pakistan: A Case Study of Bahawalpur District with Special Reference to Cholistan'. Ph.D Thesis, The Islamia University of Bahawalpur: Pakistan. Available at www.ijsrp.org

[4] Development fund for South Punjab (A discussion paper based on the statistics of Development Funds allocated to South Punjab from 2003 to 2010 (PILDAT). Available at www.pildat.org

[5] Districts' Indices of Multiple Deprivations for Pakistan, 2011. Research Report No.82.

[6] Hazoor M. SABIR, Zakir HussaiN and Abdul Saboor. (2006) Determinants Of Small Farmers Poverty In The Central Punjab. J. Agri. Soc. Sci., Vol. 2, No. 1. Available at www.fspublishers.org

[7] Highlights of Pakistan Economic Survey 2014-15. Available at www.finance.gov.pk

[8] Jafri, S. M. Younas, and A. Khattak (1995) Income Inequality and Poverty in

Pakistan. The Pakistan Economic and Social Review 33:2. Available at 


\section{www.pide.org.pk}

[9] Malik, M. H. (1988). Some New Evidence on the Incidence of Poverty in Pakistan.The Pakistan Development Review 27:4.

[10] S. Akhtar, A. Saboor, A. Q. Mohsan, F. U. Hassan, A. Hussain, N. Khurshid, A. U. Khan, U. Mustafa and I. Hassan. (2015). POVERTY DYNAMICS OF RURAL PUNJAB AND OVER TIME CHANGES. The Journal of Animal \& Plant Sciences, 25(2): 572-577. Available at http://www.thejaps.org.pk/docs/v-25-02/34.pdf

[11] Sen, A. K., (1976). Poverty: An ordinal approach to measurement. J. Econ. Soc., 219-231. Available at http://www.thejaps.org.pk/docs/v-25-02/34.pdf

[12] Sen, A. K. (1999). Multidimensional poverty: Conceptual and measurement issues. Oxford University Press. Oxford. Available at http://www.thejaps.org.pk/docs/v-25-02/34.pdf

Shirazi, Naseem Shah (1993) An Analysis of Pakistan's Poverty Problem and its

[13] Alleviation Through INFAQ. Unpublished Ph.D dissertation in Economics, International Islamic University, Islamabad. Available at www.pide.org.pk

[14] Zaman, Khalid, and Bashir Ahmad Khilji, 2014."Sectoral Decomposition of Changes in Pakistan's Poverty: The New Interface",Journal of Poverty,18(4), 453-476. DOI:10.1080/10875549.2014.951984

\section{[15] www.studymode.com}

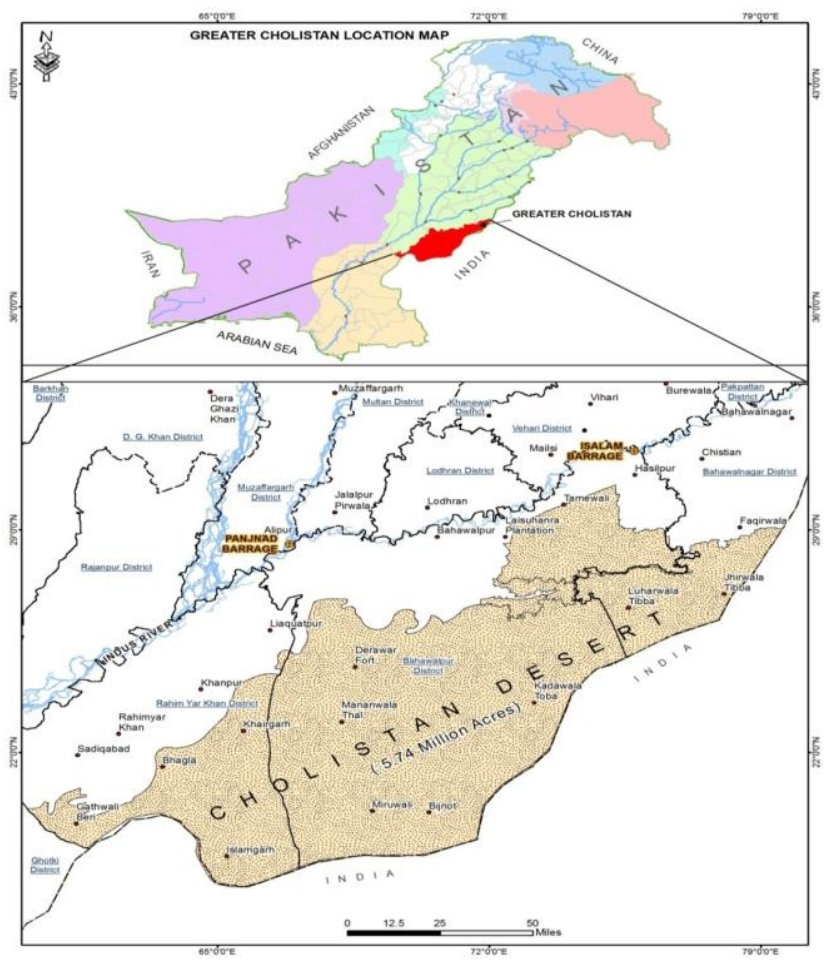

Figure 1. Cholistan location map.
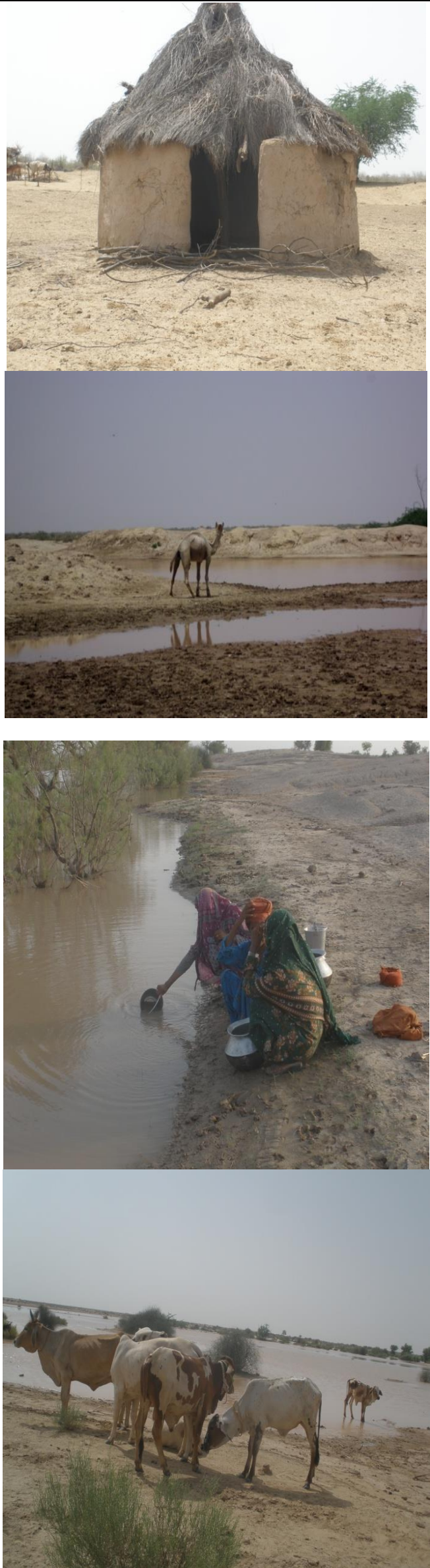
Figure 2. Features of Cholistan.

Table 1

Sampled villages of the study area.

\begin{tabular}{rccc}
\hline Sr. No. & Area & Sampled Setllements & $\%$ \\
\hline 1 & Interior Desert & 6 & 30 \\
2 & Periphery of the project area & 11 & 55 \\
3 & Canal Irrigated Cholistan & 3 & 15 \\
\hline & Total Villages & 20 & 100 \\
\hline
\end{tabular}

Table 2 Overall population and average family size of the selected villages.

\begin{tabular}{|c|c|c|c|c|}
\hline Sr. No. & Name of Settlement & Total Households & Total Population & Avg. Fannily Size \\
\hline \multicolumn{5}{|c|}{ Interior Desert (A) } \\
\hline 1 & Dolu Wala Basti & 15 & 80 & 5.0 \\
\hline 2 & Toba Chadhar Wala & 20 & 150 & 7.5 \\
\hline 3 & Pariharan Wala Toba & 40 & 200 & 5.0 \\
\hline 4 & Jamsar & 25 & 250 & 8.0 \\
\hline 5 & Toba Allah Ditta & 7 & 35 & 5.0 \\
\hline \multirow[t]{2}{*}{6} & Dabbir & 16 & 130 & 8.0 \\
\hline & Total $(\Lambda)$ & 123 & 845 & 6.9 \\
\hline \multicolumn{5}{|c|}{ Periphery of the Desert (B) } \\
\hline 7 & Talbani & 300 & 1800 & 6.0 \\
\hline 8 & Sheikh Naseer (Basti Arain) & 400 & 2400 & 6.0 \\
\hline 9 & Sheran Kot Basti & 192 & 1000 & 5.0 \\
\hline 10 & Lodhar & 150 & 800 & 5.0 \\
\hline 11 & Azafi Basti Chak 123 & 100 & 700 & 7.0 \\
\hline 12 & Chak 308 & 100 & 550 & 5.5 \\
\hline 13 & Colony Parihar (Chak311) & 200 & 1500 & 7.5 \\
\hline 14 & Baloch Colony (Chak-319 IIR) & 50 & 400 & 8.0 \\
\hline 15 & Basti Sila (Chak 302 HR) & 35 & 250 & 7.0 \\
\hline 16 & Colony (Chak 305 HR) & 50 & 400 & 8.0 \\
\hline \multirow[t]{2}{*}{17} & Chak 296-Alaf & 200 & 1800 & 9.0 \\
\hline & Total (B) & 1777 & 11600 & 6.5 \\
\hline \multicolumn{5}{|c|}{ Canal Irrigated Cholistan (C) } \\
\hline 18 & Chak $146 \mathrm{DB}$ & 80 & 700 & 8.8 \\
\hline 19 & Chak $147 \mathrm{DB}$ & 250 & 2000 & 8.0 \\
\hline 20 & Chak $148 \mathrm{DB}$ & 125 & 1200 & 9.6 \\
\hline & Total $(\mathrm{C})$ & 455 & 3900 & 8.6 \\
\hline & Total $(A+B+C)$ & 2355 & 16345 & 6.9 \\
\hline
\end{tabular}

Source: Punjab Irrigated Agriculture Investment Program (PIAlP).

Table 3 Income level of the villages selected for survey.

\begin{tabular}{|c|c|c|c|}
\hline Sr. No & Villages & Households & Average Monthly Income(PKRs.) \\
\hline \multicolumn{4}{|c|}{ Interior Desert (A) } \\
\hline 1 & Dolu Wala Basti & 15 & 12000 \\
\hline 2 & Toba Chadhar Walia & 20 & 10000 \\
\hline 3 & Pariharan Wala Toba & 40 & 8000 \\
\hline 4 & Jannsar & 25 & 9000 \\
\hline 5 & Toba Allah Dittal & 7 & 9000 \\
\hline 6 & Dabbir & 16 & 9000 \\
\hline \multicolumn{4}{|c|}{ Periphery of the Projecl Area (B) } \\
\hline 7 & Talbani & 300 & 10000 \\
\hline 8 & Sheikh Naseet (Basti Arain) & $\begin{array}{l}300 \\
100\end{array}$ & $\begin{array}{l}15000 \\
16000\end{array}$ \\
\hline 9 & Sheran Kot Rasti & 192 & 10000 \\
\hline 10 & L.odhar & 150 & 15000 \\
\hline 11 & Azafi Basti Chak 12.3 & 100 & 10000 \\
\hline 12 & Chak 308 & 100 & 12000 \\
\hline 13 & Colony Parihar (Chak311) & 200 & 10000 \\
\hline 14 & Baloch Colony (Chak-319 HR) & 50 & 12000 \\
\hline 15 & Basti Sila (Chak 302 HR) & 35 & 10000 \\
\hline 16 & Colony (Chak 305 HR) & 50 & 12000 \\
\hline 17 & Chak 296-Mlaf & 200 & 12000 \\
\hline \multicolumn{4}{|c|}{ Irrigated Cholistan (C) } \\
\hline \multirow{2}{*}{18} & \multirow{2}{*}{$146 \mathrm{DB}$} & 70 & 13000 \\
\hline & & $\begin{array}{l}10 \\
225\end{array}$ & $\begin{array}{l}16000 \\
14000\end{array}$ \\
\hline 19 & $147 \mathrm{DB}$ & 25 & 16000 \\
\hline \multirow{2}{*}{20} & \multirow{2}{*}{$148 \mathrm{DB}$} & 110 & 13000 \\
\hline & & 15 & 16000 \\
\hline
\end{tabular}

